Vojislav M. Martinov

Univerzitet u Novom Sadu

Filozofski fakultet

Student doktorskih studija

Muzej Vojvodine

Viši kustos-istoričar

vojakshvejk@gmail.com
UDK: 811.133.1.09

DOI: 10.19090/ZJIK.2021.57-70

оригинални научни рад

\title{
POTRAGA ZA DOROM BRUDER I „EMPATIČNA DISTANCA“ PATRIKA MODIJANA ${ }^{1}$
}

SAŽETAK: Polazeći od savremenih teorija kulture sećanja na Holokaust i Drugi svetski rat, u ovom radu analiziramo roman Dora Bruder, francuskog pisca Patrika Modijana, pri čemu u obzir uziamamo i širi kontekst politika sećanja u posleratnoj Francuskoj. Na osnovu višeslojne analize teksta ustanovljene su dve suprotstavljene tendencije autora/naratora u njegovoj potrazi za tragovima nastradale jevrejske devojčice Dore Bruder. Sa jedne strane, izražena je autorova potreba za snažnom identifikacijom, a sa druge svest o nemogućnosti ostvarivanja iste. Ovaj književni postupak građenja „empatične distance“ korespondira i sa širim tendencijama „druge generacije“ u umetničkim obradama prošlosti Holokausta.

Ključne reči: Holokaust, kultura sećanja, francuska književnost, Drugi svetski rat, Patrik Modijano, Dora Bruder

Pišući ovu knjigu, odašiljem pozive kao svetlosti fara za koje, nažalost, sumnjam da mogu rasvetliti noć. Ali ipak se nadam.

(P. Modijano, Dora Bruder)

U savremenim interdisciplinarnim studijama obuhvaćenim terminom „kultura sećanja“ centralno mesto zauzima tema Holokausta, tog prelomnog događaja istorije XX veka. Jedno od važnih pitanja vezanih za umetničke obrade ovog fenomena kao traumatskog središta moderne civilizacije jeste način njegove reprezentacije. Koja će se sredstva, postupci i predstave koristiti u tematizovanju

\footnotetext{
${ }^{1}$ Rad je nastao u okviru predmeta „Rat i književni diskurs u Francuskoj“ kod prof. dr Tamare Valčić Bulić, na Interdisciplinarnim doktorskim studijama u polju društvenohumanističkih nauka na Filozofskom fakultetu u Novom Sadu.
} 
Holokausta, umnogome zavisi od medija u kojem umetnik stvara, ali sve autentične kreativne procese karakterišu i određene opšte odlike koje svedoče o vremenu nastanka i širim svetonazorima samog autora. Kada se posmatra stvaralaštvo kasnijih generacija, koje nisu bile neposredni svedoci ovog epohalnog zločina, uočljiva je određena etička nelagoda u umetničkim interpretacijama tuđeg stradanja.

Rukovođen svojim intimnim potrebama, francuski pisac Patrik Modijano u romanu Dora Bruder istražuje sudbinu mlade jevrejske devojke nestale u Holokaustu, a teškoće sa kojima se suočava odražavaju se i na specifičan književni postupak, u ovom radu definisan kao „empatična distanca“. Modijanov postupak ukazuje na ambivalencije prisutne i u drugim reprezentacijama ove tematike, a proizilazi iz osnovne etičke pozicije o nemogućnosti aproprijacije tuđeg iskustva traume.

\section{RAD NA TRAUMATSKOJ PROŠLOSTI NN TEATRA U LUBLINU}

U poljskom gradu Lublinu već preko dve decenije deluje nesvakidašnja, kompleksna institucija pod nazivom Gradska kapija - NN teatar. Ime nosi po jednoj od kapija koje su obezbeđivale ulaz u staro, srednjovekovno jezgro Lublina, podignuto na brdu okruženom današnjim modernim gradom od blizu 400.000 stanovnika. Bočna vrata unutar gradske kapije vode u prostorije ove organizacije, koja je prvo počela da deluje kao eksperimentalni teatar, da bi danas prerasla $\mathrm{u}$ jednu od najznačajnih poljskih institucija posvećenih očuvanju sećanja na poljske Jevreje.

Grad Lublin je do Drugog svetskog rata imao veoma brojnu jevrejsku zajednicu, koja je činila više od trećine stanovništva, uglavnom nastanjenu u neposrednom okruženju Starog grada. Njihova getoizacija, a potom i odvođenje u logore za uništenje, pre svega u obližnji Majdanek, otpočeli su već 1939, nakon nemačke okupacije Poljske. Čitava jevrejska populacija Lublina, koja je brojala preko 25.000 stanovnika, potpuno je uništena tokom Operacije Rajnhard, kojom je rukovođeno upravo iz Lublina.

Svesni teškog nasleđa svog grada, lublinski aktivisti i umetnici su želeli da ožive sećanja na svoje stradale sugrađane, prvo pomoću predstava i brojnih uličnih aktivnosti, a potom i formiranjem jedinstvene izložbene postavke. Umesto klasičnog muzejskog izlaganja, aktivisti $N N$ teatra su iskoristili izlomljen i kompleksan prostor unutrašnjosti stana smeštenog unutar gradskih zidina (brojna stepeništa, male prostorije, hodnike), kao sredstvo za prenošenje brojnih 
fragmentiranih priča o prošlosti lublinskih Jevreja, posredstvom malobrojnih artefakata, fotografija, ali i audio i video zapisa i umetničkih instalacija. Međutim, ono što je prisutno u skoro svim prostorijama i što posetiocu privlači pažnju jesu brojne arhivske kutije - folderi sa imenima i podacima stradalih. Unutar ovih kutija se nalaze svi mogući dostupni podaci vezani za svako pojedinačno jevrejsko ime koje je nastanjivalo Lublin pre nacističke okupacije. Dok se u nekim kutijama može naći mnoštvo informacija - o mestu boravka, mestu i vremenu stradanja, imenima članova porodice, pa i poneka fotografija - u drugima se često ne nalazi ništa osim samog imena stradale ličnosti. Ipak, za svakog pojedinca je predviđena jedna kutija - kao zadatak za istraživače i kao nada da će jednog dana ova kutija moći da se popuni i da se sećanje na tu ličnost spase od zaborava. Brojne kancelarije, hodnici i stepeništa $N N$ teatra ispunjeni arhivskim folderima na vizuelnom planu svedoče o masovnosti stradanja lublinskih Jevreja, ali i o velikom odsustvu i praznini koja je nastala iz njih. Ova izložbena postavka na mnogo efektniji, konkretniji i empatičniji način uspeva da prezentuje gubitak nastao anihilacijom čitave jedne zajednice i kulture - pa samim tim i razmere samog Holokausta, od ustaljenih vizuelnih predstava logora i stradanja, koje su u stanju da nas potresu i afektivno pomere, ali ne uvek i da dočaraju razmere ovog zločina.

Nema sumnje da je projekat dokumentovanja čitave stradale zajednice utopijski. On nikada neće biti kompletiran i celovit, ali je sam rad na njemu najbolji primer onoga što teorija prepoznaje kao „rad na prošlosti“, kao nikada nedovršeno prevazilaženje, koje je ipak borba za izlazak iz „melanholije“ gubitka. ${ }^{2}$ Sakupljanje i prerada dokumenata ili fotografija kao istorijskih fakata u ovoj formi poprima aktivističku dimenziju. Ono je u službi borbe protiv zaborava - protiv zaboravljanja jedne uništene zajednice, ali i protiv zaboravljanja počinjenog zločina i ideologije koja je taj zločin inspirisala. Ipak, između dokumenta i samog događaja ostaje i ostaće zjapeća praznina, koja se ne može popuniti. Nečije ime, broj godina, mesto stanovanja, eventualni lik sa fotografije ili slike, omogućavaju posmatraču da stupi u empatični odnos sa žrtvom, ali on nikada ne može pristupiti njegovoj patnji i iskustvu.

Sličnim kontradiktornim emocijama prožet je i odnos Patrika Modijana prema devojci Dori Bruder kao objektu njegovog istraživanja i kao paradigmi stradanja francuskih Jevreja. Vođeni istim etičkim stavom, književnik i konceptualni umetnici $N N$ teatra došli su do jedne poetike koja postaje važna

\footnotetext{
2 O pojmovima ,acting out“ $\mathrm{i}$,,working through“ i njihovom međusobnom odnosu, preuzetim iz psihoanalize i primenjenim na književnu teoriju i teorije sećanja, videti: La Capra, Dominck, Writing History, writing Trauma, Baltimore, Maryland, 2014.
} 
odlika reprezentacije Holokausta u vreme u kojem su glasovi živih svedoka sve malobrojniji.

\section{POSTSEĆANJE KAO SEĆANJE DRUGE GENERACIJE}

Primer prezentacije sećanja vezanog za Holokaust iz lublinskog NN teatra ukazuje nam na ključnu pojavu prisutnu u savremenim književnim, likovnim, filmskim i drugim umetničkim reprezentacijma Holokausta, poznatu u savremenom diskursu kulture sećanja kao postsećanje - kako ga je definisala američka teoretičarka Marijana Hirš (Marianne Hirsch). U užem smislu, postsećanje se odnosi na drugu generaciju Jevreja čiji su roditelji preživeli Holokaust, a koji su i sami u formiranju sopstvenog identiteta i poimanja prošlosti neminovno bili izloženi sećanjima, predstavama, naracijama, ali i nemuštim iskustvima, kao i ćutnji sopstvenih roditelja. Na taj način i oni su sami bili posredno izloženi traumama svojih prethodnika, ali je, bez ličnog i telesnog iskustva užasa, ta trauma uvek posredna, falična, nedostatna (Hirsch 2012: 29-40). Austrijsko-američka psihoanalitičarka Judit Kestenberg tvrdila je da deca preživelih imaju stalnu težnju ka (pr)oživljavanju prošlosti roditelja, kako bi mogla da je izmene - čime bi njihova poniženja i poraze preobrazili u pobedu nad tlačiteljem (Aarons \& Berger 2017: 58). Karakteristična za narative druge generacije jeste konstantna svest o neadekvatnoj aproprijaciji roditeljske traume, koja istovremeno i jeste i nije njihova. Ovo emotivno stanje se, često, u umetničkom izrazu druge generacije manifestuje u formi ambivalencije, u tenziji između poriva za identifikacijom sa žrtvom i nemogućnosti ostvarivanja iste.

$\mathrm{U}$ širem smislu, diskurs o Holokaustu je sa protokom vremena $\mathrm{i}$ izumiranja živih svedoka takođe poprimio odlike karakteristične za postsećanje druge generacije. Kao što se vidi na primeru lublinskog $N N$ teatra, on često zadobija pseudoarhivsku formu. U ovim projektima beleženja, odnosno evidentiranja stradanja, vidljiva je implicitna potreba da se spreči „druga smrt“ žrtava koju putem zaborava proizvodi vreme sámo. Zato je istraživanje i pisanje neka vrsta protivotrova, kojim se teži održavanju sećanja i sprečavanju ponovnog umiranja kroz zaborav (Karpf 2013: 90). I sami pripadnici druge generacije ovim putem deluju kako bi ostvarili jedino spasavanje koje im je dostupno - spasavanje od zaborava, a ne od smrti (Karpf 2013: 89). 


\section{PATRIK MODIJANO U KONTEKSTU FRANCUSKE KULTURE SEĆANJA}

Patrik Modijano, francuski književnik jevrejskog porekla, istaknuti je pripadnik druge generacije, sin Jevrejina koji je bekstvom iz policije izbegao hapšenje i odvođenje u Aušvic 1942. Iako rođen neposredno nakon oslobođenja 1945. godine, Patrik Modijano je obeležen iskustvom Drugog svetskog rata i jevrejske zajednice u Francuskoj, o čemu svedoče njegova brojna dela pisana na ove teme. Unutar francuskog književnog polja Modijano se svrstava u grupu pisaca koji su početkom sedamdesetih godina XX veka napravali iskorake $\mathrm{u}$ destabilisanju hegemonih sećanja na Drugi svetski rat, kojima je dominirala pobednička retorika francuskog predsednika Šarla de Gola.

Prema istraživanjima istoričara Anrija Rusoa, tokom prve posleratne decenije u Francuskoj je nastupila faza „nedovršenog žaljenja“ i delimičnog suočavanja sa višijevskim nasleđem kolaboracije i saradnje sa nacistima. Povratkom Šarla de Gola na vlast i formiranjem Pete republike 1958, sećanje na Drugi svetski rat ušlo je u novu fazu. Francuska je usvojila simplifikovanu predstavu o nacionalnom herojstvu i žrtvi podnetoj u borbi protiv nacističkih zavojevača. Unutar tog mita, u kojem je glorifikovana i akcentovana samo uloga Pokreta otpora kao jedinog reprezenta francuskog duha, nije bilo mesta za priče o višijevskoj Francuskoj, o kolaboraciji i saučesništvu francuskih građana i o fašističkim tendencijama koje su postojale i u francuskom društvu. Ni sam Holokaust, kao događaj koji nadilazi priču o francuskoj sudbini u ovom razdoblju, tada još nije stekao status zasebne teme u istoriografiji i umetnosti (Golsan 2006: 74). Upravo su Modijanova dela istorijskog karaktera aktuelizovala mnoge od prećutkivanih i izbegavanih tema Drugog svetskog rata. Već sa svojim prvim romanom La place de l'Étoile iz 1968. godine Modijano je nagovestio generacijsku promenu u tretiranju rata, stavljajući u centar interesovanja sudbinu jevrejskih stanovnika Francuske (Golsan 2006: 77). Poseban uspeh, ali i kontroverze izazvao je i igrani film Lakomb Lisjen (Lacombe Lucien, 1974), za koji je scenario pisao Modijano. U ovom filmu se, posredstvom priče o sudbini mladića iz provincije koji igrom slučaja pristupa redovima višijevskog režima, destabilišu ustaljene predstave o francuskom kolaboracionizmu, odnosu žrtve i zločinca, kao i o odnosu ideologije i istorijske stvarnosti (Sanyal 2009: 93-94).

U vreme Modijanovog pisanja Dore Bruder, početkom devedesetih godina XX veka, u Francuskoj je već uveliko nastupila nova faza u politikama sećanja na Drugi svetski rat, koju su karakterisali oštrije sukobljavanje sa prošlošću kolaboracije i učešća višijevskog režima u Holokaustu i pokretanje novih sudskih 
procesa protiv ratnih zločinaca (Golsan 2006: 75). Iz ovih procesa, koji su imali i širi, evropski kontekst, nastajala je nova, globalna politika sećanja koja je ostala dominantna do danas.

\section{DETEKTIVSKA POTRAGA ZA SENKAMA PROŠLOSTI}

Neveliki roman Dora Bruder Modijano je pisao u vremenskom rasponu od osam godina, tokom kojih je obavljao brojna arhivska i terenska istraživanja, koja su pretočena u književnu naraciju. U ovom pseudodetektivskom romanu narator, ispostaviće se kasnije - sam autor, motivisan kratkom novinskom informacijom, sprovodi istraživanje o sudbini jevrejske devojke Dore Bruder, čiji se kratki životni vek okončao u Aušvicu.

Suočenog sa oskudnošću dostupnih informacija i podataka, naratora istraživanje vodi u mnoge rukavce kojima se kontekstualizuje i istorizuje Dorina sudbina. Osim arhivskog rada, istraživanje je sprovođeno i na terenu, posećivanjem lokacija koje je obilazila i sama Dora. Tokom samog istraživačkog procesa, naratorova lična sećanja prodiru u tekst, udvajajući se i preplićući sa osnovnim tokom priče. Naracija povremeno isklizava iz osnovnog toka, vremenski i tematski obuhvatajući mnogo širi opseg tema - od pokušaja rekonstrukcije biografije Dorinog oca, preko fragmenata iz života pojedinaca iz Dorinog mogućeg ličnog okruženja, do autorovih ličnih životnih iskustava, koja se dovode u posrednu, često asocijativnu vezu sa glavnom junakinjom romana.

Istraživanjem o Dori Bruder, autor posredno iznosi priču i o životu svoga oca, kojem je pretila ista sudbina kao i junakinji romana, a sa kojim je, pokazaće se, Modijano imao nelagodan i distantan odnos. U pojedinim trenucima, a podstaknut nekim novim podatkom o Dori, Modijano zastranjuje u sasvim drugu priču - priču o ocu, koja je latentno uvek prisutna i preti da svakog trenutka u potpunosti preuzme glavni tok romana. Jasno je da je autorov nagon za identifikacijom sa Dorom samo prikrivena potreba za njegovom identifikacijom sa ocem, sa kojim nikada nije uspeo da uspostavi toplinu i prisnost.

$\mathrm{Na}$ drugoj ravni pak, otkrivanjem istorijskih dokumenata, ali i njihovim interpretiranjem i kontekstualizovanjem, Modijano postepeno proširuje i produbljuje predstavu o epohi u kojoj je živela Dora Bruder, a posredno čitaocu pripoveda i mnogo veću, a istinitu, priču o položaju jevrejske zajednice u Francuskoj u vreme okupacije, kao i o dubinskim vezama Pariza, njegovih ulica, adresa, institucija, lokacija, sa najstrašnijim zločinom savremene evropske civilizacije - Holokaustom. Nema sumnje da su Modijanove konstatacije o 
zaturenim i uništenim dokumentima, o srušenim i izbrisanim mestima mučenja $i$ stradanja, implicitna kritika i francuske politike sećanja na Holokaust, koja je u vreme pisanja ovog dela još uvek bila gotovo nepostojeća. U trenutku u kojem je autor počeo da radi na svom istraživanju, u Francuskoj je već bio objavljen čuveni trotomni zbornik radova istoričara Pjera Nore (Pierre Nora) Les Lieux de Mémoire (Mesta sećanja) iz 1984. godine, koji će uspostaviti novu istraživačku paradigmu u oblasti kulture sećanja. Među radovima iz ovog zbornika nalazi se i tekst Pjera Birnbauma (Pierre Birnbaum) koji se bavi upravo odsustvom javnog sećanja na jevrejsku zajednicu u Francuskoj, između ostalog ukazujući i na neobeležena mesta jevrejskog stradanja u Parizu (Birnbaum 1996: 379-380). ${ }^{3}$

Od samog početka romana, naraciju prati izvesna nelagoda, tenzija koja je konstantno prisutna, a koja proizilazi iz autorovog osnovnog nemogućeg zahteva za identifikacijom sa odbeglom devojkom. Upravo ta želja za poistovećivanjem i nemogućnost njene realizacije jedna je od osnovnih karakteristika, već spomenutog, kompleksa postsećanja druge generacije. Modijano, i sam pripadnik ove generacije, odlučuje da uspostavi odnos prema traumatičnoj prošlosti zajednice kojoj po poreklu pripada, pa i prema očevoj prošlosti i ličnom iskustvu, prošlosti latentno i dalje prisutnoj u gradu u kojem autor stvara i obitava. Svoj kreativni pokušaj suočavanja sa prošlošću, pokušaj unapred osuđen na neuspeh, Modijano ostvaruje oksimoronskim građenjem ,empatične distance“ prema odsutnoj junakinji svog romana.

\section{JALOVA POTRAGA ZA TUĐIM ISKUSTVOM}

Od svog prvog susreta sa imenom Dore Bruder u jednom novinskom oglasu, Modijano se upušta u pokušaj emotivne identifikacije sa ovom jevrejskom devojkom, odbeglom iz katoličkog internata, u koji je smeštena kako bi bila sakrivena od nacističkog progona. U svojoj potrazi autor se, pre svega, okreće istorijskim izvorima, ne bi li došao do informacija koje bi mu omogućile da premosti vremensku, pa i emotivnu distancu. Svaki podatak, svaka informacija do koje autor dopire, otvara mu novu mogućnost uživljavanja.

Čitavu istragu, zapravo, inicira prvobitni trenutak identifikacije autora sa nestalom devojčicom, prouzorokovan jednim detaljem iz novinskog oglasa. U pitanju je adresa porodice Bruder - „Bulevar Ornano 41, Pariz“, blizu koje je

\footnotetext{
${ }^{3}$ Povodom veze ovog teksta sa romanom „Dora Bruder“ videti: Green, Mary Jean, Pepole Who Leave No Trace: Dora Bruder and the French Immigrant Community, Studies in 20th \& 21th Century Literature, 31/2, 444.
} 
Modijano često prolazio u svojim dečačkim šetnjama sa majkom. Bulevar Ornano ga je podsetio i na godine njegovog sazrevanja, pre svega na period od 1965. do 1968, tokom kojeg je često posećivao ovu ulicu - zbog devojke koja je živela u tom kraju, ali i zbog bioskopa koji se nalazio na broju 43, odmah do adrese navedene u starim novinama (Modijano 2014: 5-7).

Inspirisan ovom inicijalnom poveznicom, Modijano se okreće arhivskom istraživanju. Nakon prevazilaženja manjih zakonskih prepreka, narator dolazi do krštenice Dore Bruder, iz koje saznaje njen datum rođenja, njeno emigrantsko poreklo, kao i imena roditelja, što mu je otvorilo i nove rukavce za istraživanje. Tako su, na primer, biografski podaci o Dorinom ocu Ernestu, koji je iz Beča došao u Francusku nakon služenja u Legiji stranaca, naratora vratili u šezdesete godine XX veka, kada je i sam boravio u austrijskoj prestonici i obilazio krajeve koje su nekada nastanjivali brojni bečki Jevreji. Narator pokušava i da rekonstruiše moguća stratišta na kojima se borio legionar Ernest Bruder gušeći pobune u francuskim kolonijama.

U svojim pokušajima rekonstrukcije Dorinog života, Modijano, u duhu vrsnog istoričara, koristi brojne i raznovrsne istorijske izvore: policijske izveštaje, školske arhive, novinske članke. U jednom trenutku narator čak analizira i izveštaje o vremenskim prilikama u vreme Dorinog boravka na ulici. Upravo mu ovakvi izvori otvaraju još jednu moguću liniju identifikacije, jer su takva iskustva - iskustva kiše, snega, hladnoće - u izvesnoj meri univerzalna i omogućavaju poistovećivanje sa Dorom, makar na tom elementarnom nivou. Isto tako, on analizira i bioskopski repertoar koji je verovatno bio aktuelan i u bioskopu Ornano, u neposrednoj blizini Dorinog doma, u nadi da će ga gledanje filmova koje je možda i ona gledala nekako zbližiti sa jevrejskom devojkom i da će ostvariti identično iskustvo. Ipak, gledajući jednu romantičnu komediju emitovanu u vreme Dorinog bekstva, Modijano se nije mogao odupreti naknadnim učitavanjima proisteklim iz pozicije svedoka istorije:

Brzo sam shvatio da je taj film bio natopljen pogledima gledalaca za vreme okupacije - gledalaca svih vrsta, od kojih veliki broj nije preživeo rat. [...] I svi su ti pogledi nekom vrstom hemijske reakcije izmenili sastav same trake, osvetljenje, pa i glasove glumaca. Eto šta sam osetio, razmišljajući o Dori Bruder, pred tim, naizgled, lepršavim prizorima Prvog ljubavnog sastanka (Modijano 2014: 77). 
Ipak, svi ti dokumenti, izvori, novinski članci koje autor iščitava - samo su skromni ostaci, delići stvarnosti, nedostatni u svojoj šturosti da dočaraju emotivni svet Dore Bruder, koji on žudi da oseti.

Kako bi saznao više i preskočio vremenski jaz koji zjapi između dokumenata i njihovog tumača, narator se okreće i malobrojnim živim izvorima. On stupa u kontakt sa preživelom rođakom porodice Bruder, od koje opet dobija samo oskudne podatke o Dorinim roditeljima, o njihovom životu pre rata i manji broj biografskih podataka o samoj Dori. Modijano upoznaje i jednu osobu koja je kao mala boravila $u$ istom internatu, ali njena sećanja su skromna i autor opet ostaje bez ikakvih novih informacija o Dori. Ta retka svedočenja kao da su samo produbljivala autorovu rezigniranost. Kada je saznao da je nastojnica internata preminula svega nekoliko godina pre njegovog istraživanja, Modijano se nije mnogo potresao zbog propuštene prilike da stekne nova saznanja: „Ali, napokon, šta bih od nje i mogao da saznam? Nekoliko pojedinosti, malih svakodnevnih detalja. Ma koliko plemenita bila, ona sigurno nije mogla odgonetnuti šta se dešavalo u glavi Dore Bruder..." (Modijano 2014: 40).

Svoja arhivska i istoriografska istraživanja Modijano upotpunjuje nesvakidašnjim postupkom. On se okreće gradu Parizu i njegovim prostorima za koje veruje da čuvaju sećanje na potisnutu prošlost, tražeći da ostvari kontakt na konkretnim lokacijama - na mestima i ulicama kojima se Dora kretala i na kojima je bivstvovala: „Kažu da mesta života čuvaju neki lagani otisak osoba koje su ih nastanjivale. Otisak u vidu udubljenja i ispupčenja. Za Ernesta i Ceciliju Bruder, rekao bih, u vidu udubljenja. Uvek sam imao onaj doživljaj odsustva i praznine kad bih se našao na mestima gde su oni živeli“ (Modijano 2014: 25-26).

Obilazeći ulice za koje osnovano sumnja da ih je i sama Dora videla, autor nastoji da oživi emocije svoje junakinje. Na odabranim lokacijama on traga za znakovima, za signalima koji će probuditi i produbiti njegovu imaginaciju. Ipak, i ovi pokušaji stupanja u kontakt sa duhom Dore Bruder ostaju bez uspeha. Internat iz kojeg je Dora pobegla više ne postoji. Ne postoji ni logor u koji je bila internirana pre konačnog puta za Aušvic. Talozi vremena su već suviše veliki i umesto kontakta, autora ispunjava samo osećaj odsustva. On, međutim, i odsustvo želi da tumači kao ostatak, kao znak: „Pa ipak, ispod debelih naslaga amnezije, s vremena na vreme, jasno se oseća nešto što se ne može tačno odrediti, kao neki udaljeni, prigušeni eho. To je kao naći se na rubu jednog magnetnog polja, bez igle koja hvata njegove talase" (Modijano 2014: 127-128).

Snažna želja autora da se identifikuje sa Dorom vidljiva je tokom čitavog romana. Ovu težnju on pokušava da mistifikuje, da je predstavi kao 
predodređenost. Analizirajući retroaktivno sopstvena iskustva vezana za lokacije na kojima je boravila i Dora Bruder, on ih doživljava kao prekogniciju, pripisujući sebi čak i vidovitost, iako je jasno da su u pitanju tek slabe koincidencije. Uprkos tako snažnim emotivnim porivima, narator se sve vreme suočava sa nepremostivim jazom između sebe i objekta svoje želje.

\section{NEPREMOSTIVI JAZ IZMEDU SUBJEKATA U VREMENU}

Kako napreduje potraga za Dorom Bruder, sve više raste broj informacija, podataka, činjenica. Autor akumulira sve više znanja i pretpostavki o samoj junakinji, njenoj sudbini, o Parizu 1942. godine, o zakonima i uslovima života Jevreja u okupiranom gradu. Deluje da Modijano raspolaže sasvim dovoljnom količinom podataka da se upusti u književni poduhvat - u literarnu obradu jedne biografije i njenu istorijsku kontekstualizaciju. Ipak, autor to nijednog trenutka ne pokušava. On se ne usuđuje na poslednji korak imaginacije i na konačno uživljavanje u svet Dore Bruder. Modijano ne dopušta sebi luksuz poistovećivanja sa žrtvom, sa njenim emocijama, traumama, strahovima. Umesto priče o glavnoj junakinji, on nam donosi priču o neuspehu traganja za njenom pričom, o neuspehu identifikacije, o distanci između pisca i Dore Bruder koju stvaraju istorijski dokumenti, naslage vremena, kao i autorove lične emocije.

Porinuvši u arhive u potrazi za Dorom Bruder, Modijano se suočio sa emocijom sa kojom se suočava svaki istraživač i istoričar jezivih zločina XX veka. U pitanju je mrtvi govor dokumenata koji hladno i nezainteresovano svedoče o stradanjima i užasima, o razorenim životima i sudbinama. Susret sa ovim birokratskim svedočanstvima, umesto da je smanjuje, kao da dodatno povećava distancu između posmatrača i događaja. Modijano oseća ovu distancu i sam je potcrtava tišinom koja nastupi nakon prezentovanja novog dokumenta do kojeg je došao u svojoj istrazi. Ova tišina se oseti i manifestuje kroz oskudne i nedovršene analize koje uslede nakon tumačenja određenog dokumenta.

Slična tišina koja prati dokumente možda je i najvidljivija u naratorovom susretu sa malobrojnim fotografijama Dore Bruder. Te fotografije, inače izrazito potentno sredstvo za rad imaginacije, za uživljavanje i premošćavanje vremenske distance, kod Modijana, čini se, ne pokreću nikakvu identifikaciju. Nakon što dâ detaljnu deskripciju ambijenta i izgleda Dore Bruder na tih pet-šest fotografija, autor gotovo iznenada završava poglavlje, ostavivši čitaoca željnog dublje analize, a u svesnom pokušaju da suspenduje svoju maštu i eventualnu dublju emocionalnu reakciju (Modijano 2014: 28-30). 
Oslanjajući se na pribavljene informacije, narator se ponekad usudi da ih iskoristi i da, na osnovu raspoloživog znanja, nagovesti kakvo je bilo moguće ponašanje, kretanje ili razmišljanje Dore Bruder. Uvek je to samo pokušaj i uvek tek samo fragment, samo detalj mogućeg Dorinog života. Ovo uživljavanje, međutim, ni tada nije potpuno. Narator u tim situacijama jasno naglašava da je u pitanju tek njegova spekulacija i nagađanje (,,pitam se da li...“; „možda je..."), a kako priča odmiče, upitnici se samo gomilaju, bez ikakvog izgleda da će na njih biti odgovoreno.

Osećaj neuhvatljivosti i izmicanja prisutan je i u Modijanovom terenskom istraživanju. On ima ambivalentan odnos prema ovim ličnim „mestima sećanja“ koja ga istovremeno približavaju i udaljavaju od Dore Bruder: „Imam utisak da sam jedina spona između Pariza onog vremena i ovog sada, jedini koji se seća svih pojedinosti. Ima trenutaka kada se veza tanji i preti da se pokida i dugih večeri kada mi današnji grad izgleda kao skrivena slika jučerašnjeg“ (Modijano 2014: 47).

Preko pola veka je prošlo od događaja koje autor želi da reprodukuje i Pariza po kojem se sam kreće, a gotovo ništa nije zadržalo ondašnji izgled. Naslage decenija prekrile su stvarnost okupiranog Pariza. Internat „Svetog srca Marijinog“ odavno je srušen. Od velikog sabirnog logora Dransi ostala je samo tabla „Dransi, Romenvil“ na putu za aerodrom Roasi. Jedino su objekti zatvora Turel, u kojima je Dora boravila pre transporta u Dransi, još bili na mestu, ali opasani zidovima sa upozorenjem: „Vojni krug. Zabranjeno snimati i fotografisati“. „Izgledalo mi je da se više niko ničega ne seća“, konstatuje narator, „... iza zida prostire se no man's land, pojas praznine i zaborava“ (Modijano 2014: 127). Kao da je vreme izbrisalo sve tragove sveta u kojem je obitavala Dora, pa osim ,,ispupčenja“ i ,udubljenja“ koja Modijano učitava u zatečeni prostor, jaz vremena onemogućava puno prožimanje iskustva za kojim teži.

Možda i najvećem jazu između Dore i autora doprinose upravo njegovo lično iskustvo, emocije i sećanja, koji mu neprestano smetaju u potrazi. Dokumenta, svedočanstva, informacije do kojih autor dolazi, ne približavaju ga Dori niti doprinose nekom novom zaključku i daljem promišljanju, već samo pokreću asocijacije na lična iskustva. Adrese koje je Dora posećivala podsećaju ga na ulice kojima je sam lutao i na ljude koje je poznavao. Razmišljanja o Dorinom bekstvu vraćaju ga u godine njegove mladosti, kada se i sam odvažio na taj smeli korak. Ipak, najintenzivnija sećanja koja autoru budi ova istraga jesu sećanja na oca. Hodnici zgrade suda, u koju je autor došao po dozvolu za dobijanje Dorine krštenice, bude mu sećanje na koridore bolnice u kojoj je njegov otac ležao na 
samrti. Isto tako, istraživanje delatnosti Policije za jevrejska pitanja naratora podstiče na neprijatnu ispovest o ličnom privođenju, sprovedenom na inicijativu samog autorovog oca, nakon beznačajne rasprave oko alimentacije. Asocijacije i paralele koje se samom autoru nameću u toku istrage, čini se, deluju nategnuto i neumesno. Kako i sam kaže, nakon digresije o brojnim piscima stradalim pred sam kraj rata:

I oni i svi ostali, neposredno pre mog rođenja, iscrpli su sve zalihe patnje, ostavivši nam da podnosimo samo neke male jade. Shvatio sam to već oko osamnaeste godine, tokom onog putovanja sa ocem u marici - putovanja koje nije bilo ništa drugo do bezopasno ponavljanje i parodija onih drugih, u takvim istim kolima i prema istim policijskim komesarijatima, ali sa kojih se nikada nije vraćalo svojoj kući pešice, kao što sam ja učinio toga dana (Modijano 2014: 97).

Uprkos brojnim kognitivnim i imaginativnim naporima, autor do samoga kraja nije uspeo da ostvari željenu bliskost za devojčicom iz oglasa iz 1941. Umesto potpunog uživljavanja, uranjanja u svet Dore Bruder, u njene emocije strahove, nadanja i žudnje, nastao je tekst kao svedočanstvo o porazu autora, o nesavladivoj distanci koja ga deli od njegove junakinje, što je Modijano i sumirao u dirljivom poslednjem pasusu:

Nikada neću saznati kako je provodila svoje dane, gde se skrivala, u čijem se društvu nalazila onih zimskih meseci posle svog prvog bekstva ili kada je, u proleće, ponovo iščezla na nekoliko sedmica. I tu je njena tajna. Mala i dragocena tajna koju dželati, naredbe, vlast koja se zove okupacijskom, zatvori, kasarne, logori, istorija ili vreme - sve ono što nas prlja i razara nikada nisu bili kadri da joj ukradu (Modijano 2014: 140).

*** *

Roman Dora Bruder Patrika Modijana slojevito je i višeznačno delo koje na suptilan način uvezuje autorova lična iskustva i velike, često subverzivne teme iz savremene francuske istorije. Fokus analize u ovom radu stavljen je na samo jedan aspekt romana - na autorov postupak pisanja o Holokaustu. Taj postupak ima odlike postsećanja prisutnog među potomcima evropskih Jevreja, koji su preživeli strahote Drugog svetskog rata. Neke od odlika postsećanja su posredna traumatizacija, ali i nemogućnost potpune identifikacije sa proživljenim iskustvom roditelja. U romanu Dora Bruder ova tenzija se manifestuje kroz neuspeh 
identifikacije autora sa sudbinom jevrejske devojke Dore. Posredstvom istoriografskih istraživanja, on pokušava da stupi u empatični odnos sa Dorom, ali mu u ovom pokušaju smetaju njegova lična iskustva, emocije i sećanja. Umesto potpunog uživljavanja i rekreiranja Dorinog iskustva, autor svesno zadržava distancu, ne želeći da prisvoji tuđu traumu.

\section{LITERATURA}

Aarons, V. \& Berger, L. A. eds. 2017. Third-Generation Holocaust Representation: Trauma, History and Memory, Illinois, Northwestern University Press.

Birnbaum, Pierre. 1996. "Grégoire, Dreyfus, Drancy, and the Rue Copernic: Jews at the Heart of French History". In: Nora, P. and Kritzmann, D. L. eds. Realms of Memory: The Construction of the French Past, I, New York, Columbia Unversity Press, 379-423.

Golsan, J. Richard. 2006. "The Legacy of World War II in France: Mapping the Discourses of Memory". In: Lebow, N. E. et al. eds. The Politics of Memory in Postwar Europe, Durham and London, Duke Univesity Press: 73-101.

Green, Mary Jean. 2007. "Pepole Who Leave No Trace: Dora Bruder and the French Immigrant Community", Studies in 20th \& 21th Century Literature 31(2): 434-449.

Hirsch, Marianne. 2012. The Generation of Postmemory: Writing and Visual Culture after the Holocaust, New York, Columbia University Press.

Karpf, Anne. 2013. "Chain of Testimony: The Holocaust Researcher as Surrogate Witness". In: Chare N. and Williams D. eds. Representing Auschwitz: At the Margins of Testimony, London, Palgrave McMillan: 85-103.

La Capra, Dominck. 2014. Writing History, writing Trauma, Baltimore, Johns Hopkins University Press.

Modijano, Patrik. 2014. Dora Bruder, Novi Sad, Akademska knjiga. (prevela sa francuskog Mirjana Uaknin).

Sanyal, Debaranti. 2009. “The French War" In: MacKay, M. ed. The Cambridge Companion to the Literature of the World War II, Cambridge, Cambridge University Press: 83-97. 
Vojislav M. Martinov

THE SEARCH FOR DORA BRUDER AND PATRICK MODIANO’S „EMPHATIC DISTANCE“

\section{Summary}

In this paper, we analyze the novel Dora Bruder by the French novelist Patrick Modiano, with the emphasis on contemporary theories on the cultural memory of World War Two and Holocaust, as well as taking into account the politics of memory in postwar France. Based on the analysis of the novel, we identify author's/narrator's two opposing tendencies that developed during his search for archival remains of Dora Bruder, a Jewish girl killed in the Holocaust. On the one hand, there is a strong need for the author to relate to Dora's experiences, but on the other, his inability to approach the trauma of the Other. This literary procedure of building up ,emphatic distance“ corresponds with broader tendencies of the „second generation“ in artistic representations of the Holocaust.

Key words: Holocaust, cultural memory, French literature, WWII, Patrick Modiano, Dora Bruder 